\title{
Optimisation of shear strengthened reinforced concrete beams
}

Hiran D. Yapa BScEng, PhD

Lecturer, Department of Civil Engineering, Faculty of Engineering,

University of Peradeniya, Peradeniya, Sri Lanka
Janet M. Lees BEng, MSc, PhD, DIC, MICE, CEng

Reader in Civil Engineering, Department of Engineering, University of

Cambridge, Cambridge, UK

External prestressed carbon fibre reinforced polymer straps can be used to strengthen shear-deficient reinforced concrete structures. For an efficient shear retrofitting system, the optimum combinations of parameters such as the number of straps, strap locations, strap stiffness and initial strap prestress need to be identified. The modified compression field theory and the shear friction theory have previously been applied to carbon fibre reinforced polymer strap strengthened beams. As implemented, both of these methods are iterative. Particle swarm optimisation and genetic algorithm stochastic optimisation methods were used to reduce the computational cost associated with the shear strength evaluation and also to search the design space for carbon fibre reinforced polymer strap strengthened beams. An initial comparison across several test functions showed that the preferred optimisation algorithm depended on the characteristics of the design space. When applied to a reinforced concrete case study, the genetic algorithm was better for searching the shear friction theory shear strength design space that was characterised by several peaks. However, for the smoother modified compression field theory shear strength evaluation space, and for the design space for the carbon fibre reinforced polymer strengthened beams calculated using either the modified compression field theory or the shear friction theory, the particle swarm optimisation converged more quickly and accurately. The optimised solutions reflect the assumptions within the underlying evaluation methods.

\section{Notation}

$a_{\mathrm{g}}$

$b_{\mathrm{w}}$

$c 1, c 2$

$E_{\mathrm{s}}$

$F_{\text {FRP }}$

$f_{\mathrm{c}}^{\prime}$

$f_{\mathrm{s} x}, f_{\mathrm{s} z}, f_{z_{-} \mathrm{FRP}}$

$f_{\mathrm{sxcr}}, f_{\mathrm{szcr}}$

$f_{x}, f_{z}$

$f_{\mathrm{y} x}, f_{\mathrm{y} z}$

$f_{1}, f_{2}$

$g_{\text {best }}$

h

$k$

$k_{\mathrm{c}}$

$N_{\mathrm{v}}, N_{\mathrm{p}}$

$n_{\mathrm{L}}, n_{\mathrm{P}}, n_{\mathrm{S}}$

$P_{\mathrm{c}}, P_{\mathrm{i}}, P_{\mathrm{m}}$ shear span

aggregate size

beam web width

learning factors

Young's modulus of elasticity of steel

strap force

concrete cylinder compressive strength

stress in the longitudinal steel, stress in the

transverse steel, mid-depth transverse stress due

to the strap force

stresses at crack in the $x$ and $z$ directions

average stress in the $x$ and $z$ directions

steel yield stress in $x$ and $z$ directions

principal concrete stresses

best solution achieved by all the particles

beam height

shear friction coefficient

confined area ratio

population size

force due to internal stresses and force in the longitudinal reinforcement

number of layers per strap, level of initial

prestress and number of straps

crossover, inversion and mutation probabilities $p_{\text {best }} \quad$ best solution each particle has achieved

$R \quad$ force perpendicular to shear crack plane

rand random number between 0 and 1

$S \quad$ resultant force along shear crack plane

$S 1, S 2, S 3 \quad$ CFRP strap spacings

$s_{x}, s_{z}, s_{\theta} \quad$ crack spacing in $x, z$ and $\theta$ directions

$T_{\mathrm{V}} \quad$ force in internal steel stirrup

$V \quad$ shear strength

$V_{\text {fle }} \quad$ shear force associated with flexural failure

$V_{\max }, V_{\min } \quad$ velocity limits

$V_{\mathrm{t}} \quad$ velocity at the $t$ th iteration

$v \quad$ shear stress

$v_{\text {ci }} \quad$ shear stress along the crack

$w \quad$ crack width

$w_{\mathrm{IF}} \quad$ inertia factor

$X \quad$ distance from support

$X_{\text {range } \quad \text { range }}$

$X_{t} \quad$ position at the $t$ th iteration

$x_{\text {opt_algo }}, y_{\text {opt_algo }}$

algorithm optimum

$x_{\text {opt }}, y_{\text {opt }} \quad$ actual optimum

$\beta \quad$ shear crack angle

$\gamma_{\mathrm{xz}} \quad$ shear strain

$\varepsilon_{x}, \varepsilon_{z} \quad$ strain in longitudinal and transverse directions

$\varepsilon_{\mathrm{z} \_ \text {ini }} \quad$ initial vertical strain 


$$
\begin{array}{ll}
\varepsilon_{1}, \varepsilon_{2} & \text { principal strains } \\
\theta & \begin{array}{l}
\text { inclination of the principal compressive strain } \\
\text { direction relative to the } x \text { (longitudinal) direction }
\end{array} \\
\rho_{x, \rho_{z}} & \begin{array}{l}
\text { steel reinforcement ratio in the longitudinal and } \\
\text { transverse directions }
\end{array}
\end{array}
$$

\section{Introduction}

Shear failures in reinforced concrete (RC) structures are typically brittle and sudden. Shear deficiencies can arise due to increased loading, corrosion of the internal steel reinforcement and less conservative designs based on earlier design codes (Lees et al., 2002). A lack of strength leads to the need either to impose weight limits, to strengthen the structure or to demolish and replace it. The strengthening of structures with insufficient shear capacity is therefore an attractive option. Various fibre reinforced polymer retrofitting systems including surface bonded systems (Teng et al., 2004), near surface mounted systems (De Lorenzis and Nanni, 2001) and unbonded strap systems (Lees et al., 2002) have been investigated.

A carbon fibre reinforced polymer (CFRP) strap system is the subject of the current work and is shown schematically in Figure 1. The straps are unbonded and can be prestressed to augment the confinement supplied to the concrete and to mitigate crack opening and propagation. The system has been investigated for rectangular (Kesse and Lees, 2007a) or slab-on-beam structures (Hoult and Lees, 2009a). The CFRP strap is made by winding layers of thin (between $0 \cdot 12 \mathrm{~mm}$ and $0 \cdot 16 \mathrm{~mm}$ thick) continuous CFRP thermoplastic tape around the beam. Profiled steel bearing pads provide a smooth support for the CFRP strap. The two outermost tape layers are welded so as to form a complete self-anchored non-laminated loop (Lees and Winistörfer, 2011; Winistörfer, 1999). More details about the system and the method of prestressing can be found elsewhere (Kesse and Lees, 2007a; Yapa, 2011).

In an unstrengthened RC structure the internal steel reinforcement is in the form of discrete units with a particular size (bar diameter) that resist tensile forces. The CFRP straps add further discrete units of transverse reinforcement in which the number of straps, strap location, strap stiffness and initial strap prestress can vary. The challenge is to ascertain both the base strength of the unstrengthened structure and the design of the required strengthening system that will be most efficient. There is no common agreement about the best evaluation method to determine the shear capacity of unstrengthened or strengthened RC beams.

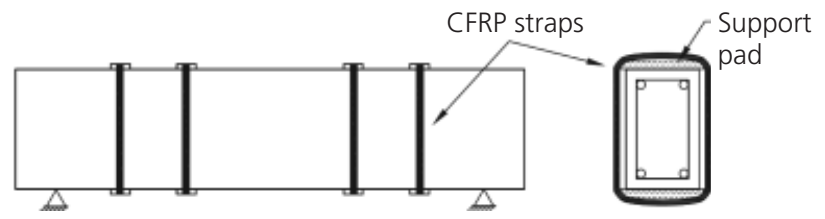

Figure 1. Prestressed carbon fibre reinforced polymer strap shear strengthening system
However, with some modifications, the shear friction theory (SFT) (Loov, 1998) and the modified compression field theory (MCFT) (Vecchio and Collins, 1986) have been adapted to predict the capacity of CFRP strap strengthened beams (Hoult and Lees, 2009b; Lees et al., 2002; Yapa, 2011). Finite-element analysis methods (Dirar et al., 2013; Kesse and Lees, 2007b) were not considered further in the current study due to the computational complexity in meshing and analysing a multitude of strengthening combinations (in the context of optimum parameter search), the difficulty in the selection of appropriate input parameters and the desirability of an analytical model.

Stochastic optimisation methods will be investigated to help streamline the shear strength evaluation and CFRP strap strengthening design processes. Stochastic methods do not use derivative information and the objective function does not need to be explicitly defined in terms of the design variables. The exact optimum cannot be guaranteed but often an exact solution is not necessary and a near solution can be attained even for highly constrained problems with many variables (Rafiq and Southcombe, 1998). Stochastic optimisation has been previously applied to RC structural engineering applications including RC beam design optimisation (Matous et al., 2000), RC frame design optimisation (Govindaraj and Ramasami, 2007) and the cost optimisation of RC flat slabs (Sahab et al., 2005). In the current work, optimisation methods will be used for two separate purposes: to reduce the number of iterations in the theoretical evaluation of the shear strength of RC beams; and to identify the strengthening system locations and parameters to achieve the largest shear capacity enhancement.

\section{Stochastic optimisation methods}

Common stochastic optimisation methods for engineering include Monte Carlo sampling (MCS), genetic algorithms (GA), particle swarm optimisation (PSO), simulated annealing and Tabu search (Yang et al., 2006). However, Wolpert and Macready (1997) state that

\footnotetext{
. .if some algorithm $\mathrm{a}_{1}$ 's performance is superior to that of another algorithm $\mathrm{a}_{2}$ over some set of optimization problems, then the reverse must be true over the set of all other optimization problems.
}

This means that there is no universally superior algorithm for all possible cost functions. The potential trade-offs between two selected optimisation methods in the context of the shear behaviour of CFRP strengthened RC structures will be studied. The particular focus will be the GA and PSO methods because they are robust, they work with a set of solutions rather than a single solution and can possess a fast convergence rate when compared with other stochastic optimisation techniques (Hu, 2006).

\subsection{Particle swarm optimisation}

PSO is a technique inspired by the social behaviour of flocks of birds or schools of fish (Hu, 2006). PSO is based on cooperation rather than competition (Liu et al., 2007) and the PSO population is stable. Hence individuals are neither destroyed nor created but 
instead are updated. Updating is mainly influenced by the best performance of solution neighbours. Advantages of the PSO method include: it works with real numbers; there are relatively few control parameters that need to be tuned; the algorithm is comparatively easy to implement; and for most problems, ten particles (solutions) are sufficient to achieve a good result so the associated computational cost is low (Hu, 2006).

The PSO is initialised with a group of random particle positions. The algorithm then searches for the optima by updating the solution group. The $p_{\text {best }}$ solution is the best solution each particle has achieved so far and the $g_{\text {best }}$ solution is the best solution achieved by all the particles. The position (value) and velocity at the $t$ th iteration are defined as $X_{t}$ and $V_{t}$, respectively. To make the algorithm more efficient Shi and Eberhart (1998) introduced a linearly decreasing inertia factor, $w_{\mathrm{IF}}$, into the velocity update equation in which

$$
\begin{aligned}
\quad V_{t+1}= & w_{\mathrm{IF}} \times V_{t}+c 1 \times \text { rand } \times\left(p_{\text {best }}-X_{t}\right) \\
1 . \quad & +c 2 \times \text { rand } \times\left(g_{\text {best }}-X_{t}\right)
\end{aligned}
$$

and $c 1$ and $c 2$ are learning factors, usually equal to two (Hu, 2006), rand is a random number between 0 and 1 , and $w_{\mathrm{IF}}$ decreases linearly from 0.9 to $0 \cdot 4$ through the iteration process. The latter measure is taken to allow the particles to move freely at the initial stage of the search to avoid becoming trapped in a local minimum and to control the particle movements at the later stage of the search to ensure a fast convergence.

For each particle, the new particle position at the next iteration (after a unit time increment) $X_{t+1}$ is found as

$$
\text { 2. } X_{t+1}=X_{t}+V_{t+1} \times 1
$$

The initial velocity of each particle is set to zero and the subsequent updated velocities are bounded within the range of $V_{\max }$ and $V_{\min }$ where

3. $V_{\max }=\frac{X_{\text {range }}}{2} ; V_{\min }=-\frac{X_{\text {range }}}{2}$

and $X_{\text {range }}$ is the specified potential range for the variable (Liu et $a l ., 2007)$. If the velocity exceeds either of these thresholds, the corresponding threshold value is assigned.

\subsection{Genetic algorithms}

GAs are based on the mechanics of natural selection and natural genetics (Goldberg, 1989). GAs are good at handling cases in which the objective function is characterised by a number of sharp peaks (Keane, 1995). Although GAs locate the neighbourhood of the global optimum efficiently there can be problems in convergence onto the optimum itself (Rafiq and Southcombe, 1998). GAs differ from other stochastic optimisation procedures primarily because they work with a coding of the parameter set and not the parameters themselves, and they search for multiple points from a population so the probability of finding a false peak is reduced. Traditionally, GA solutions are represented by binary bit strings, but can also work with natural numbers (Matous et al., 2000). Full details of the method can be found elsewhere (Goldberg, 1989).

An initial population of solutions is generated. The algorithm evaluates the fitness of these solutions by comparing the objective function value of the solution with the sum of the objective function values of all the solutions in the population where

4. $\quad$ Fitness $=\frac{f(\text { solution })}{\sum_{\text {all }} f(\text { solution })}$

The fittest solutions are then selected through a reproduction process. These reproduced solutions are directed to a mating pool, which is subsequently subjected to genetic operations. The genetic operations include crossover, inversion and mutation. In the crossover operator two parent individuals are selected with a probability ' $P_{\mathrm{c}}$ ' from the population and recombined to form two new individuals. Although there are different crossover methods (Goldberg, 1989) the traditional 'one point crossover' is used in the current work. Inversion is an advanced optional GA operator that can make the algorithm more efficient but comes at an increased computational cost (Goldberg, 1989). A single string is selected with a probability ' $P_{\mathrm{i}}$ ' and two arbitrary points are chosen along the length of the string. The string is then cut at these points, and replaced in the reverse order. Mutation helps to avoid the trapping of the GA in a local optimum by changing single bits of individuals to another value.

\subsubsection{Control parameters}

The efficiency of a GA is highly dependent on the algorithm's control parameter values. Assuming that features such as the selection procedure (reproduction) are predetermined, the adjustable control parameters are the population size $N$, crossover probability $P_{\mathrm{c}}$, mutation probability $P_{\mathrm{m}}$ and inversion probability $P_{\mathrm{i}}$. Exact values for these control parameters are not defined but, for an efficient search, potential ranges have been proposed: $20 \leqslant N \leqslant 60,0.75 \leqslant P_{\mathrm{c}} \leqslant 0.95, P_{\mathrm{i}} \approx 0.5$ and $0.001 \leqslant P_{\mathrm{m}} \leqslant 0.05$ (Goldberg, 1989). Suitable control parameter values can be chosen from experience or through a trial and error process.

\subsection{Verification}

The PSO and GA were coded and verified using six test functions that represent a diverse range of topologies. These functions were (see also Figure 2)

Rosenbrock function

5. $f(x, y)=(1-x)^{2}+100\left(y-x^{2}\right)^{2}$ 
Engineering and Computational Mechanics Volume 167 Issue EM2
Optimisation of shear strengthened reinforced concrete beams

Yapa and Lees

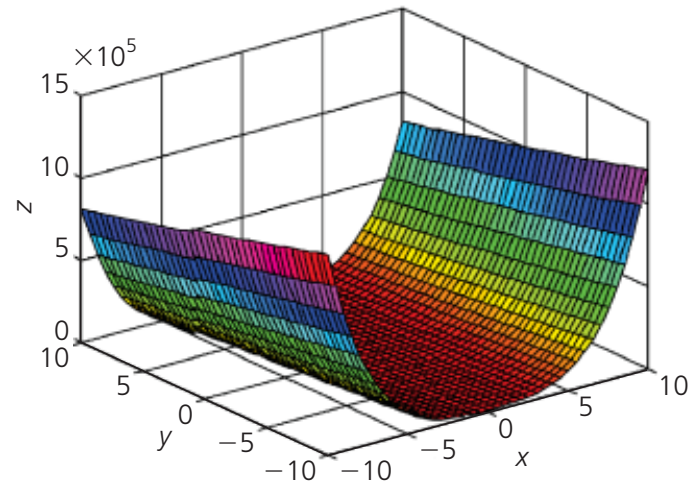

(a)

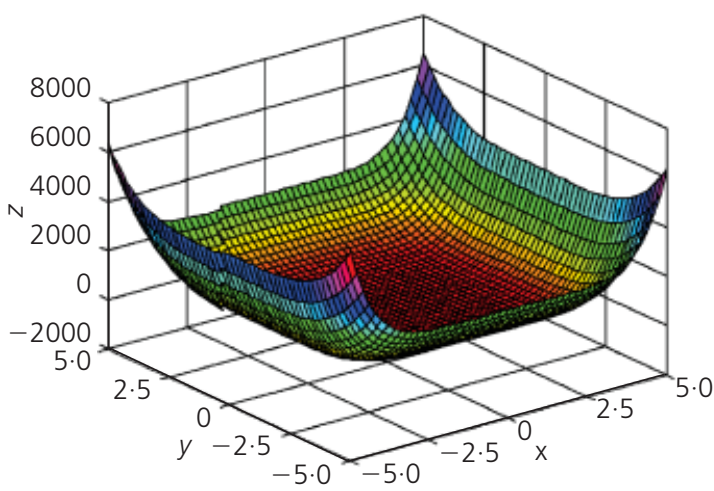

(c)

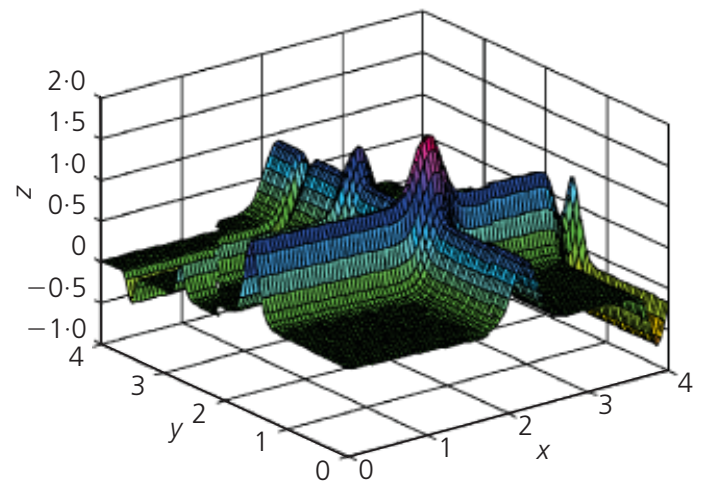

(e)

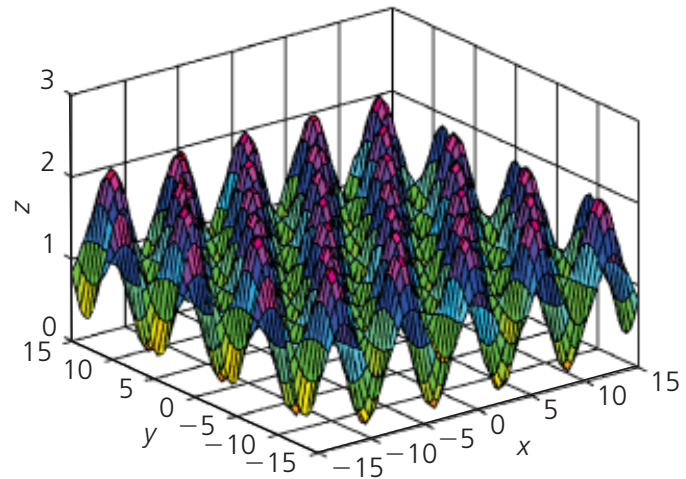

(b)

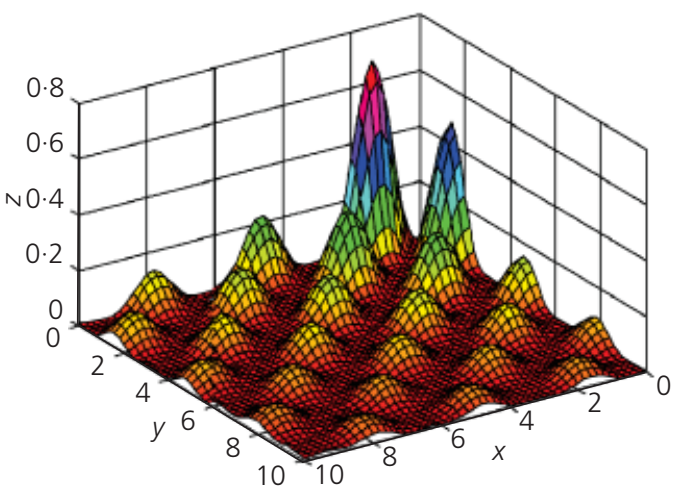

(d)

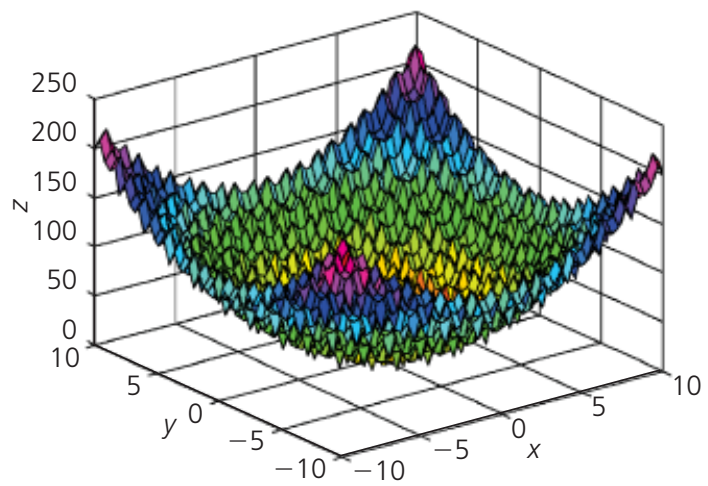

(f)

Figure 2. Test functions: (a) Rosenbrock function; (b) Griewank function; (c) Hump function; (d) Keane function; (e) Michalewicz function; (f) Rastrigin function

Griewank function

6. $f(x, y)=\frac{x^{2}+y^{2}}{4000}-\cos (x) \cos \left(\frac{y}{\sqrt{2}}\right)+1$
Keane function

8.

$$
f(x, y)=\frac{\sin ^{2}(x-y) \sin ^{2}(x+y)}{\sqrt{x^{2}+2 y^{2}}}
$$

Hump function

7. $f(x, y)=4 x^{2}-2 \cdot 1 x^{4}+\frac{1}{3} x^{6}+x y-4 y^{2}+4 y^{4}$

\section{Michalewicz function}

9. $f(x, y)=\sin (x) \sin ^{20}\left(\frac{x^{2}}{\pi}\right)+\sin (y) \sin ^{20}\left(\frac{2 y^{2}}{\pi}\right)$ 
Rastrigin function

10. $f(x, y)=x^{2}+y^{2}-10 \cos (2 \pi x)-10 \cos (2 \pi y)+20$

In the test function verification process, the GA control parameter values were varied within the potential ranges and the computational cost to generate the target optimum was compared for each test function. It was found that, $P_{\mathrm{c}}=0.8, P_{\mathrm{i}}=0.5$ and $P_{\mathrm{m}}=0.05$ were reasonable GA control parameter values. A population size $N=40$ was generally found to be sufficient and for some test functions was in excess of what was necessary.

Ten repeat runs were undertaken and the resulting mean and standard deviation of the error has been summarised in Table 1 for the coded PSO and GA algorithms. The number of evaluations for each search (rounded to the nearest thousand) is also noted. Convergence was considered to have been achieved when no new best solutions were found for three consecutive generations. The error of the solution was calculated as

11. Error $=\sqrt{\left(x_{\mathrm{opt}}-x_{\mathrm{opt} \_a l g o}\right)^{2}+\left(y_{\mathrm{opt}}-y_{\text {opt_algo }}\right)^{2}}$

where $x_{\text {opt_algo }}, y_{\text {opt_algo }}$ and $x_{\mathrm{opt}}, y_{\mathrm{opt}}$ are the optimum found by the algorithm and the actual optimum in terms of the $x$ and $y$ coordinates, respectively.

The verification results illustrate that, with the exception of the Griewank function, which has many identical local optimums, the PSO generally found the optima for the functions efficiently at a relatively low computational cost. The PSO became trapped in a local optimum in the Griewank function in one of the test runs, which led to a large error. The GA performed better than the PSO for the Griewank function both in terms of the number of evaluations until convergence and the error. The GA also found the optimum for the Rastrigin function, which had many local optima, with fewer evaluations. However, for the other four test functions, the PSO error was smaller after the same number of evaluations. The GA located the neighbourhood of the optimum in these functions but was not as efficient in converging onto the optimum itself.

\section{Shear strength evaluation methods}

As discussed, the shear behaviour of RC is complex and there is no universal agreement on the best shear model. A common feature of the more advanced methods is that iterations are required to evaluate the credible shear strength. Perera et al. (2009) showed that stochastic methods can be used to generate initial random solutions for an evaluation process associated with iterations, and the final solution can be achieved by updating these solutions. So optimisation can play a role in reducing the length of time for the evaluation process (hereafter referred to as 'evaluation'). The MCFT and the SFT will be used as examples of evaluation methods for unstrengthened and CFRP strengthened beams. Once the predicted strength for a given set of parameters has been calculated, optimisation methods can also be used to investigate different combinations of parameters to seek the most critical combination ('parameter searching'). The preferred optimisation technique will depend on the characteristics of the strength evaluation and parameter searching design space.

\subsection{Modified compression field theory}

The MCFT developed by Vecchio and Collins (1986) is capable of predicting the full response of cracked RC members subjected to shear and/or torsion. The theory consists of 15 main equations that are shown in Figure 3. When modelling a RC beam subjected to both bending and shear the longitudinal stress varies through the beam depth, which introduces further solution steps. In the current work the stress-strain conditions at the beam mid-depth are used and it is assumed that the shear stress and crack angle are uniform across the beam depth (Collins and Mitchell, 1987). As the theory considers strain compatibility, Lees et al. (2002) showed that in an average sense the unbonded CFRP strap

\begin{tabular}{|c|c|c|c|c|c|c|}
\hline Test function & Rosenbrock & Griewank & Hump & Keane & Michalewicz & Rastrigin \\
\hline \multicolumn{7}{|l|}{ PSO } \\
\hline $\begin{array}{l}\text { No. of evaluations } \\
\text { Error }\end{array}$ & 8000 & 8000 & 4000 & 2000 & 2000 & 4000 \\
\hline Mean & 0.001 & 0.001 & 0.000 & 0.000 & 0.000 & 0.000 \\
\hline SD & 0.002 & 0.004 & 0.000 & 0.000 & 0.000 & 0.000 \\
\hline \multicolumn{7}{|l|}{ GA } \\
\hline $\begin{array}{l}\text { No. of evaluations } \\
\text { Error }\end{array}$ & 8000 & 1000 & 4000 & 2000 & 2000 & 1000 \\
\hline Mean & 0.014 & 0.000 & 0.006 & 0.028 & 0.006 & 0.000 \\
\hline SD & 0.034 & 0.000 & 0.004 & 0.041 & 0.005 & 0.000 \\
\hline
\end{tabular}


contribution can be included in the equation for vertical equilibrium (equation 2 in Figure 3)

12. $f_{z}=\rho_{z} f_{\mathrm{s} z}+f_{z_{-} \mathrm{FRP}}+f_{1}-v \tan \theta$

where $f_{z}, \rho_{z}, f_{\mathrm{s} z}, f_{z_{-} \mathrm{FRP}}, f_{1}, v$ and $\theta$ are the total stress in the $z$ direction, steel reinforcement ratio in the $z$ direction, stress in the transverse steel, average transverse stress created at the mid-depth of the beam due to the strap force, principal tensile stress of concrete, shear stress, and inclination of the principal compressive strain direction relative to the $x$ (longitudinal) direction. Yapa and Lees (2014) proposed an approach to model RC beams retrofitted with either uniform or non-uniform strap configurations. For nonuniform or large strap spacing configurations, the shear span was considered as regions bounded by either the support and a strap, two straps, or a strap and a load point. The MCFT analysis was performed for each region and the critical region with the minimum shear strength is identified. When the strap spacing is large, the influence of the imposed vertical stress distribution becomes weak. To reflect this, a smeared vertical stress is defined using a confined area ratio $\left(k_{\mathrm{c}}\right)$. Full details of the MCFT as applied to unstrengthened (Collins and Mitchell, 1987) and CFRP strengthened beams (Yapa, 2011; Yapa and Lees, 2014) can be found elsewhere.

\subsection{Shear friction theory}

The SFT developed by Loov (1998) considers the shear reinforcement as discrete elements. Loov argues that the concrete contribution along the crack interface is a function of the normal stress on the crack plane, the concrete strength and a shear friction coefficient. When extending the SFT for the CFRP strap strengthening system, the CFRP straps are represented as additional discrete web reinforcement elements (Hoult and Lees, $2009 \mathrm{~b}$ ) and the force in the straps along the crack plane defines the CFRP strap contribution (see Figure 4). To include the strap contribution, if the force in an individual strap is $F_{\mathrm{FRP}}$, the total force carried by all the straps crossing the crack is $\Sigma F_{\mathrm{FRP}}$. The total shear strength $V$ for a given crack plane is then

13. $V=0 \cdot 25 k^{2} f_{\mathrm{c}}^{\prime} b_{\mathrm{w}} h \tan \beta+\sum T_{\mathrm{v}}+\sum F_{\mathrm{FRP}}$

where $k$ is the shear friction coefficient (which was taken as $k=0.55$ in the current work), $f_{\mathrm{c}}^{\prime}$ is the concrete cylinder compressive strength, $b_{\mathrm{w}}$ is the web width, $h$ is the height of the beam and $\beta$ is the shear crack angle relative to the horizontal. The SFT assumes that the internal shear links crossed by the shear crack have yielded at the crack so $\Sigma T_{\mathrm{v}}$ can be calculated. The CFRP straps do not have a yield

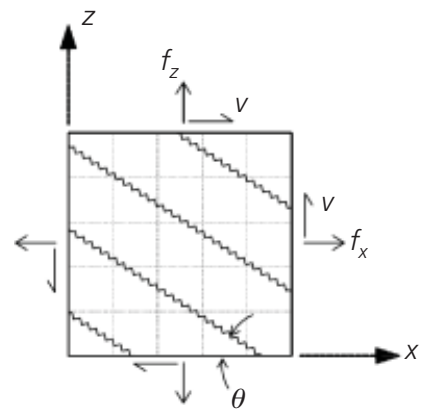

Equilibrium

Average stresses:

$$
\begin{aligned}
& f_{x}=\rho_{x} f_{s x}+f_{1}-v \cot \theta \\
& f_{z}=\rho_{z} f_{s z}+f_{1}-v \tan \theta \\
& v=\left(f_{1}+f_{2}\right) /(\tan \theta+\cot \theta)
\end{aligned}
$$

Stresses at cracks:

$$
f_{\text {sxcr }}=\left(f_{x}+v \cot \theta+v_{\mathrm{ci}} \cot \theta\right) / \rho_{x}
$$$$
f_{\mathrm{szcr}}=\left(f_{z}+v \tan \theta-v_{\mathrm{ci}} \tan \theta\right) / \rho_{z}
$$

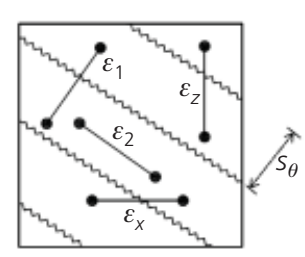

Geometric conditions Average strains:

$\tan ^{2} \theta=\frac{\varepsilon_{x}+\varepsilon_{2}}{\varepsilon_{z}+\varepsilon_{2}}$

$\varepsilon_{1}=\varepsilon_{x}+\varepsilon_{z}+\varepsilon_{2}$

$\gamma_{x z}=2\left(\varepsilon_{x}+\varepsilon_{2}\right) \cot \theta$

Crack widths:

$$
\begin{aligned}
& W=s_{\theta} \varepsilon_{1} \\
& s_{\theta}=1 /\left(\frac{\sin \theta}{S_{x}}+\frac{\cos \theta}{S_{z}}\right)
\end{aligned}
$$
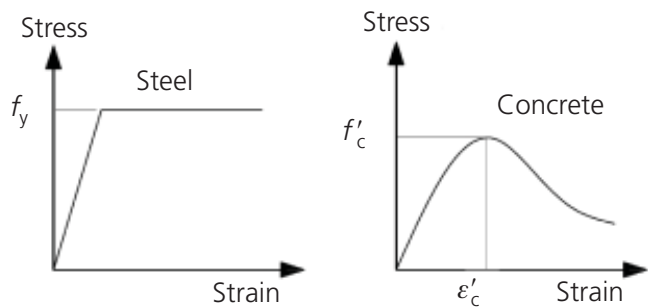

Stress-strain relationships Reinforcement:

$f_{\mathrm{sx}}=E_{\mathrm{s}} \varepsilon_{x} \leqslant f_{\mathrm{yx}}$

$f_{\mathrm{sz}}=E_{\mathrm{s}} \varepsilon_{\mathrm{z}} \leqslant f_{\mathrm{yz}}$

Concrete:

$f_{2}=\frac{f_{c}^{\prime}}{0 \cdot 8+170 \varepsilon_{1}}\left[2 \frac{\varepsilon_{2}}{\varepsilon_{c}^{\prime}}-\left(\frac{\varepsilon_{2}}{\varepsilon_{c}^{\prime}}\right)^{2}\right]$

$f_{1}=0 \cdot 33 \sqrt{f_{c}^{\prime}} /\left(1+\sqrt{500 \varepsilon_{1}}\right)$

Shear stress on crack:

$v_{\mathrm{ci}} \leqslant 0 \cdot 18 \sqrt{f_{\mathrm{c}}^{\prime}} /\left(0.31+\frac{24 w}{a_{\mathrm{g}}+16}\right)$ 


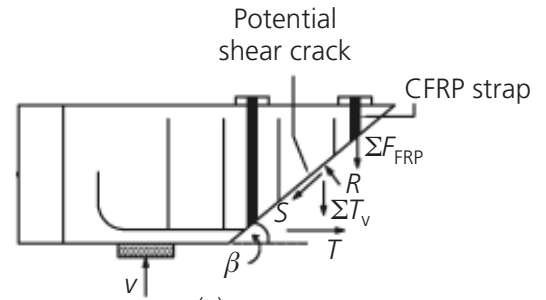

(a)

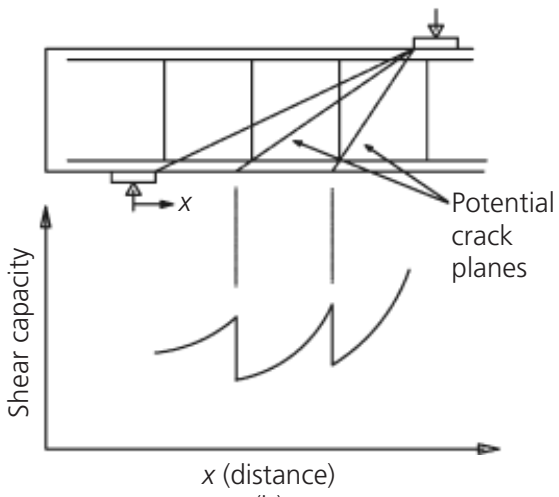

(b)

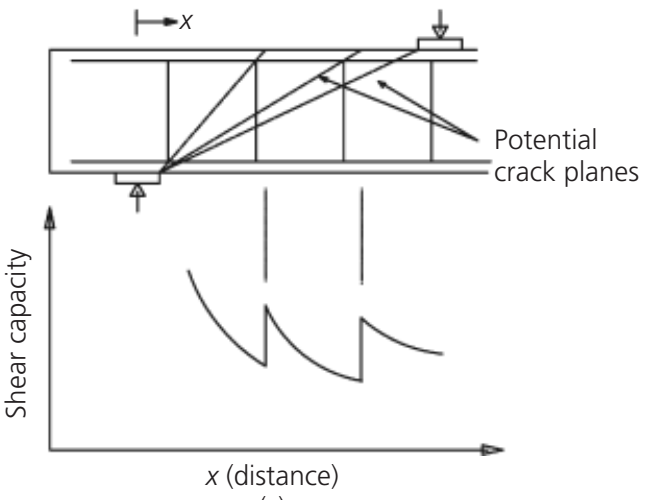

(c)

Figure 4. Shear friction theory: (a) conditions along crack plane; (b) and (c) crack plane resistance variation with $x$ and $\beta$. CFRP, carbon fibre reinforced polymer

point and are not bonded to the structure. So the crack opening results in an increase in strain along the entire length of the strap. Hoult and Lees (2009b) calibrated Loov's shear friction model with the model of Vecchio and Collins (1986), which enabled Hoult and Lees to identify the crack width variation corresponding to a given average shear stress in the SFT. The initial strap prestrain is added to the strain due to the crack opening to obtain the total strap strain which leads to $F_{\mathrm{FRP}}$ for a given strap (for full details please see Hoult and Lees, 2009b). In the SFT solution procedure all the potential shear crack planes must be evaluated to identify the critical shear crack associated with the minimum strength (see Figure 4).

\section{Application of stochastic optimisation to shear strength evaluation}

The use of stochastic methods for the evaluation of shear strength was investigated using a case study consisting of an RC beam strengthened with two CFRP straps in fixed locations. The RC beam $\left(f_{\mathrm{c}}^{\prime}=35 \mathrm{MPa}\right)$ had a cross-section of $105 \times 280 \mathrm{~mm}$, a shear span of $690 \mathrm{~mm}$, longitudinal reinforcement ratio of 3.3\% $\left(f_{\mathrm{y}}=500 \mathrm{MPa}\right)$ and $4 \mathrm{~mm}$ diameter $\left(f_{\mathrm{y}}=475 \mathrm{MPa}\right)$ steel shear links with a spacing of $200 \mathrm{~mm}$. The first shear link was $70 \mathrm{~mm}$ away from the support. The concrete cover was $25 \mathrm{~mm}$. The two ten-layer $25 \%$ prestressed CFRP straps were located at $S 1=270 \mathrm{~mm}$ and $S 2=470 \mathrm{~mm}$. The elastic modulus of the CFRP material was $120 \mathrm{GPa}$ and the bearing pad width was
$100 \mathrm{~mm}$. Note that this beam design is similar to beam B2 from an experimental investigation reported elsewhere (Yapa and Lees, 2014).

\subsection{MCFT evaluations}

For assumed increments of $\varepsilon_{1}$, MCFT solutions are obtained by iterating through other parameters until equilibrium is satisfied. In the current work, $\theta$ and $\varepsilon_{z}$ are the parameters for iteration and the focus is to find a solution that satisfies equilibrium, compatibility and the material laws thereby to identify the load capacity of the beam. The region bounded by the straps was identified as the critical shear region (see Figure 5) and $\varepsilon_{1}=0.005$ was associated with the ultimate load capacity of the beam. The confined area ratio $\left(k_{\mathrm{c}}\right)$ for this region was found to be 0.95 (see Yapa and Lees, 2014). This ratio depends only on the strap locations so therefore was a fixed value for the subsequent evaluations. The solution space was mapped (see Figure 5(b)) to assess the performance of the algorithms. This step would otherwise not be necessary. For the specified value of $\varepsilon_{1}$ the PSO and GA were used to generate initial random solutions for $\theta$ and $\varepsilon_{z}$ and subsequently update the solutions to minimise the associated error (defined in Equation 14). In the GA, the solutions are coded as floating point numbers. A population of 20 initial random solutions were generated subject to: $22^{\circ} \leqslant \theta \leqslant 45^{\circ}$ and $0.05 \times 10^{-3} \leqslant \varepsilon_{z} \leqslant 10 \times 10^{-3}$, see Figure 5(c). The objective function was the total error associated with the axial load equilibrium, which is calculated in terms of the force due to 


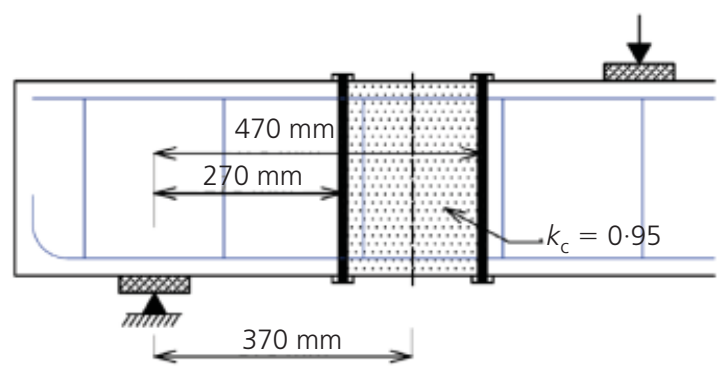

(a)

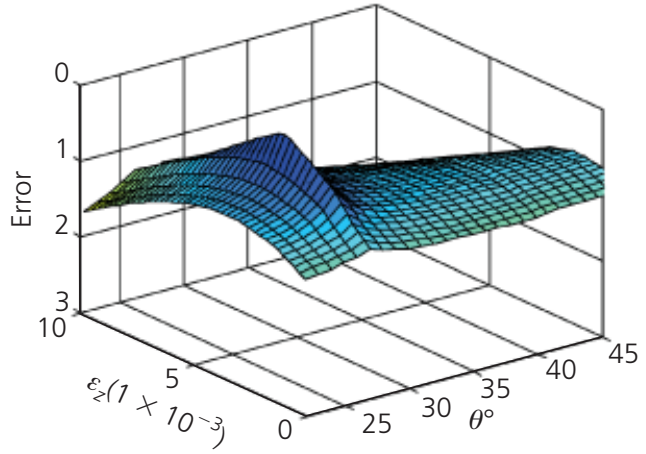

(b)

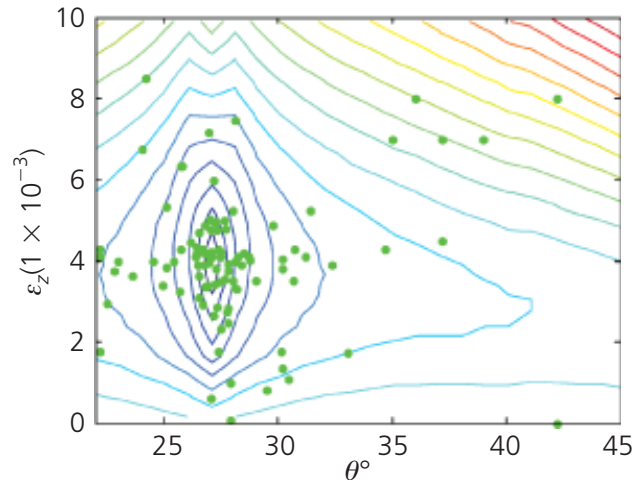

(d)

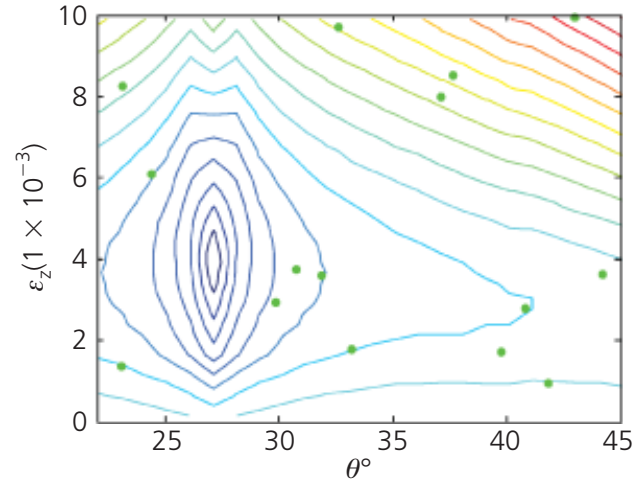

(c)

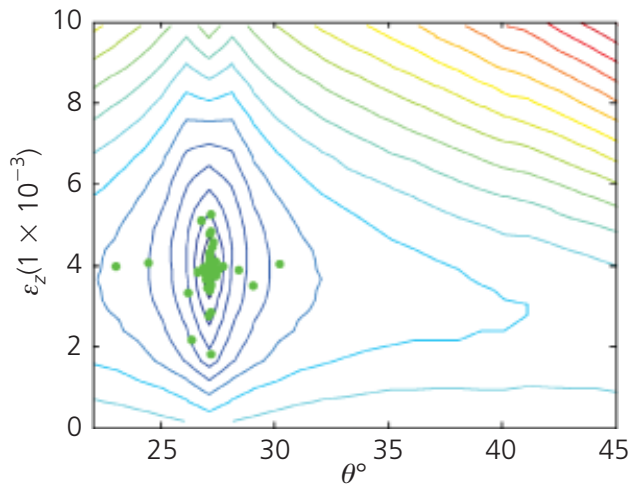

(e)

Figure 5. Use of optimisation algorithms for modified compression field theory evaluations: (a) beam design; (b) design space; (c) initial genetic algorithm (GA) and particle swarm optimisation (PSO) solutions; (d) GA solutions over 46-50 generations; (e) PSO solutions over 46-50 generations

internal stresses $\left(N_{\mathrm{v}}\right)$ and force in the longitudinal reinforcement $\left(N_{\mathrm{p}}\right)$, and the initial vertical strain $\left(\varepsilon_{z \_ \text {ini }}\right)$ and the resulting vertical strain $\varepsilon_{z}$ where

\section{4.}

$$
\text { Total error }=\sqrt{\left(\frac{N_{\mathrm{v}}-N_{\mathrm{p}}}{N_{\mathrm{v}}}\right)^{2}+\left(\frac{\varepsilon_{z_{-} \text {ini }}-\varepsilon_{z}}{\varepsilon_{z}}\right)^{2}}
$$

One potential issue with this normalisation is that the force error generally dominates. However, for the cases studied here, the minima in the force and strain error matrices tended to occur in close proximity. Figures 5(d) and 5(e), respectively, show the GA and PSO solutions during 46-50 generations. Within 50 generations (a total of 1000 evaluations), the PSO converged to a solution in which $\theta=26.3^{\circ}$ and $\varepsilon_{z}=3.9 \times 10^{-3}$ corresponding to a shear capacity of $105 \cdot 2 \mathrm{kN}$. Convergence was assumed to have been achieved when no new best solutions were found for three consecutive generations. Extending the convergence window to ten consecutive generations did not yield any new best solutions. The GA could not produce a converged solution after a similar number of evaluations. The gradual, smooth behaviour in the 
design space was the expected reason for the better performance of the PSO.

\subsection{SFT evaluations}

In the SFT, the design variables are the starting point of the crack $(x)$ and the crack angle $(\beta)$, and the objective function is the shear strength for a given crack plane. An example design space is shown in Figure 6. To improve the visualisation of the design space, the shear force has been plotted as a negative quantity. An initial random population of 20 solutions was generated, in which $50 \mathrm{~mm} \leqslant x \leqslant 650 \mathrm{~mm}$ and $20^{\circ} \leqslant \beta \leqslant 75^{\circ}$. The GA seemed to perform better with the SFT evaluations than the PSO. For example, the GA finds the shear strength for the critical shear crack to be $87.7 \mathrm{kN}$ after 20 generations, whereas after a similar number of generations the PSO had yet to converge and suggests a critical capacity of $92.5 \mathrm{kN}$. Figure 6 shows the values of the best solution in each algorithm through the generations. As the focus was to reach the minimum strength value, the result suggests that the PSO has been trapped in a local optimum. The discrete nature of the objective function and the existence of several local optima could be the reason for the better performance of the GA than the PSO in this example.

It is of note that the experimental beam (B2), which had similar characteristics to the case study beam, failed in shear at $104.7 \mathrm{kN}$ (Yapa and Lees, 2014). Thus the MCFT prediction is closer to the observed experimental value. More generally, Yapa (2011) showed that for the CFRP retrofitted beams considered in his study, the SFT fundamentally predicts a lower failure load level than the ultimate load.

\section{Application to parameter searching: optimum strap locations}

Stochastic methods were also used for parameter searching to identify the CFRP strap locations that would deliver the greatest shear strength enhancement. The methodology to find the optimum CFRP strap locations for a RC beam with a given strap stiffness and initial prestress level is summarised in the flow diagrams in Figure 7. Based on the outcomes of the previous section, the shear strengths are evaluated using the MCFT $+\mathrm{PSO}$ or SFT + GA for an initial random generation of CFRP strap locations. Subsequently, new solutions (strap locations) are generated by updating the initial solutions using either the PSO or GA optimisation algorithms for parameter searching. The evaluation and parameter optimisation steps are then repeated until the optimum shear strength of the beam is found. In the following sections, this process is described using a case study consisting of an RC beam retrofitted with two CFRP straps.

The beam dimensions, internal longitudinal and transverse steel were fixed to be the same as the previous evaluation case study. The beam flexural capacity was calculated as $114 \mathrm{kN}$ and the MCFT and SFT shear strength predictions (unstrengthened) for the design were $60.9 \mathrm{kN}$ and $57.7 \mathrm{kN}$, respectively. The strap area, stiffness and initial prestress level were the same for all the CFRP straps in a given retrofitting layout and the variables
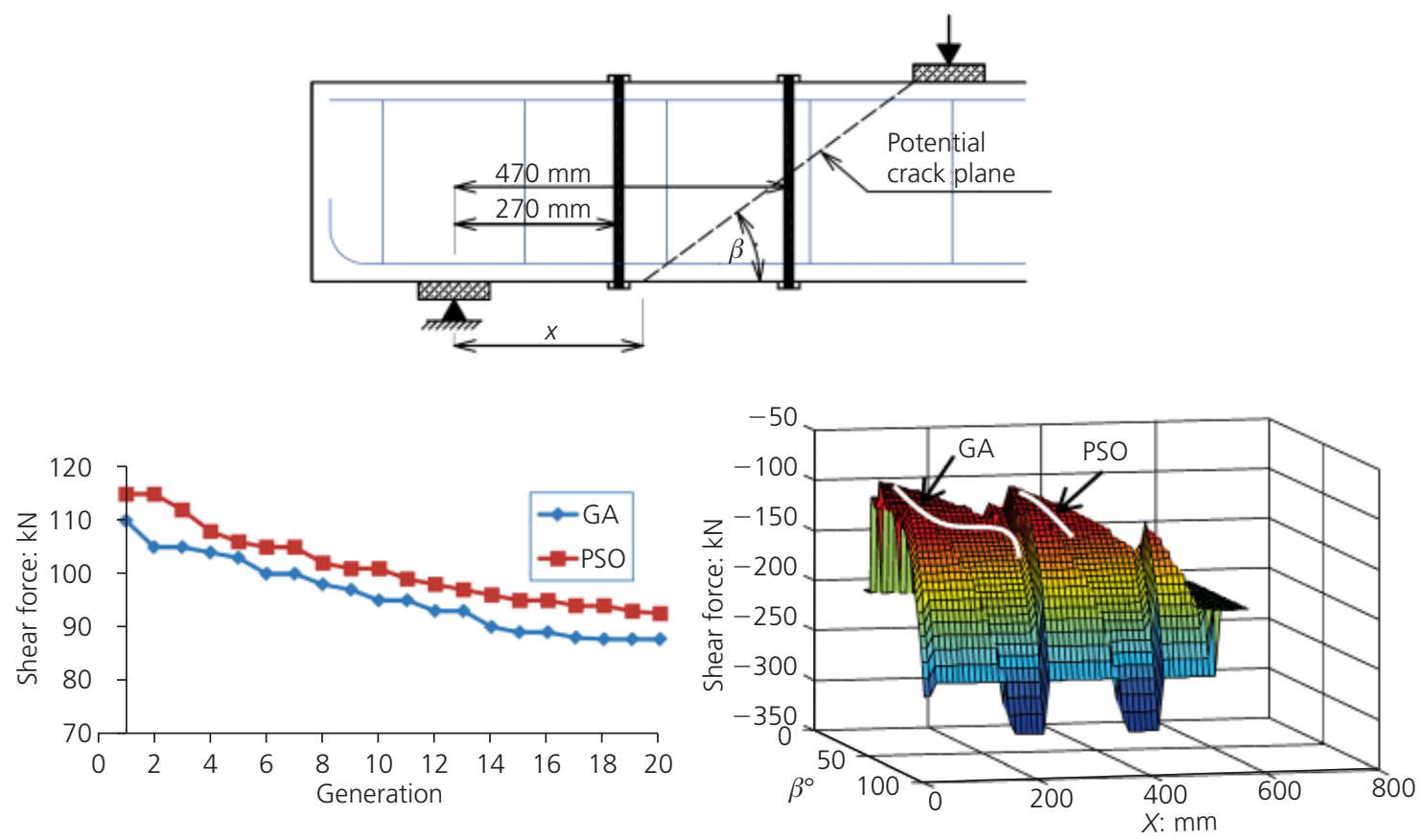

Figure 6. Shear friction theory evaluation: comparison of genetic algorithm (GA) and particle swarm optimisation (PSO) results 


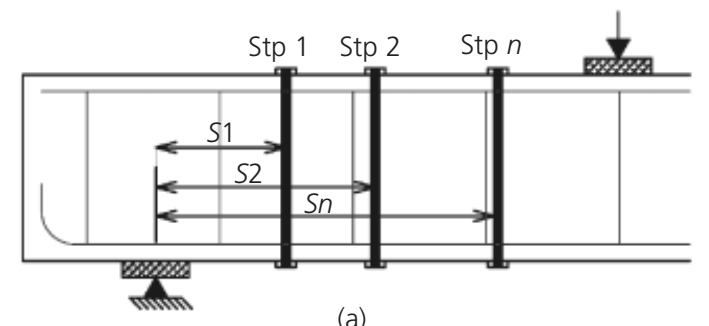

(a)

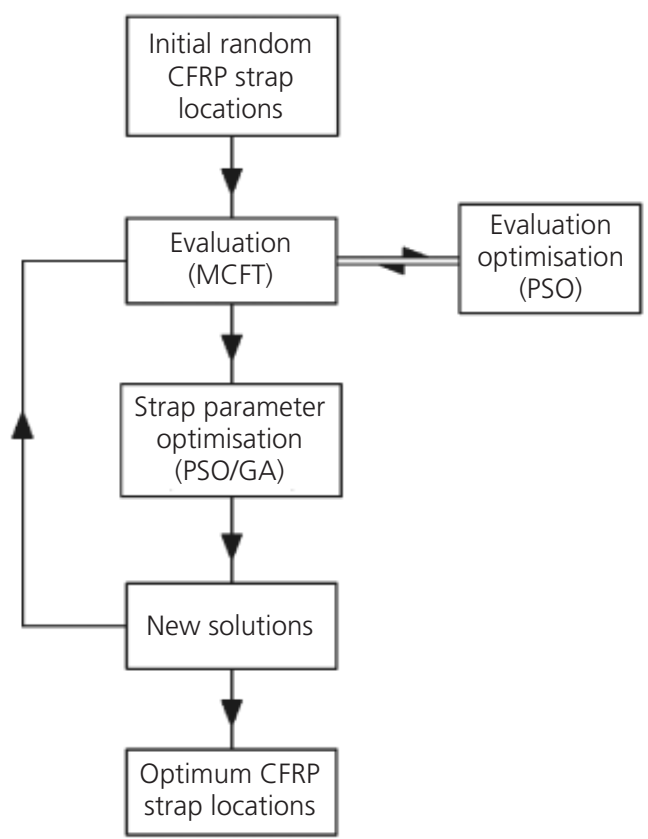

(b)

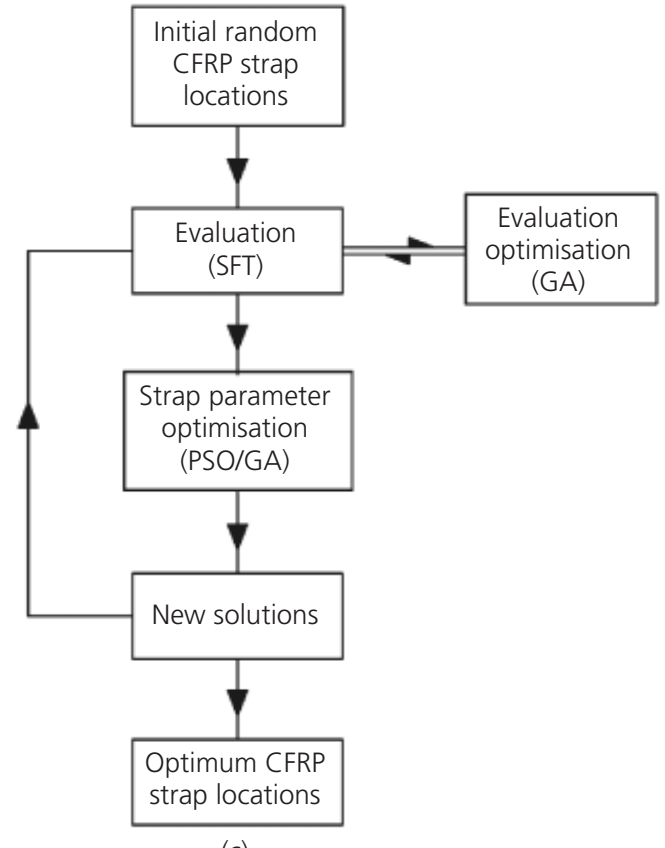

(c)

Figure 7. Flow diagrams for the optimum carbon fibre reinforced polymer (CFRP) strap location search: (a) CFRP strap configuration; (b) modified compression field theory (MCFT)-based evaluation; (c) shear friction theory (SFT)-based evaluation: GA, genetic algorithm; PSO, particle swarm optimisation

are the CFRP strap locations $(100 \mathrm{~mm} \leqslant S 1, S 2 \leqslant 600 \mathrm{~mm})$. The shear capacity for a given strap layout is the objective function. To visualise the context, the overall design space was mapped using the different evaluation techniques. A comparison of Figures 8(a) and 9(a) shows how the topology of the design space differs depending on the evaluation method. This highlights once again that the most efficient parameter searching optimisation algorithm will depend on the strengthened design shape. Ten initial random solutions were generated for $S 1$ and $S 2$ as shown in Figures 8(b) and 9(b), and the solutions were updated using the GA or PSO. The distribution of the GA and PSO solutions over 16-20 generations has also been plotted in the figures.

\subsection{MCFT and PSO with PSO or GA parameter searching}

Using the MCFT, the PSO parameter search found a converged optimum solution for $S 1=460 \mathrm{~mm}$ and $S 2=290 \mathrm{~mm}$ within 20 generations (see Figure 8(d)). This layout corresponded to a shear strength of $111.2 \mathrm{kN}$. The GA found an approximate optimum solution for the strap locations after a similar number of generations but the convergence was not as good (see Figure 8(c)). So the PSO was more efficient than the GA when finding the optimum strap locations for the relatively smooth MCFT strengthened design space.

\subsection{SFT and GA with PSO or GA parameter searching}

For the strengthened beams evaluated using the SFT, the PSO was also more efficient than the GA when finding the exact optimum solution, see Figure 9. The PSO found a converged solution after only 20 iterations where $S 1=270 \mathrm{~mm}$ and $S 2=420 \mathrm{~mm}$, corresponding to a shear strength of $96.0 \mathrm{kN}$. The GA was unable to find the exact optimum after a similar number of iterations. Note that, as observed previously, the GA has also approached the optimum in the design space, but has been unable to converge onto the optimum. 


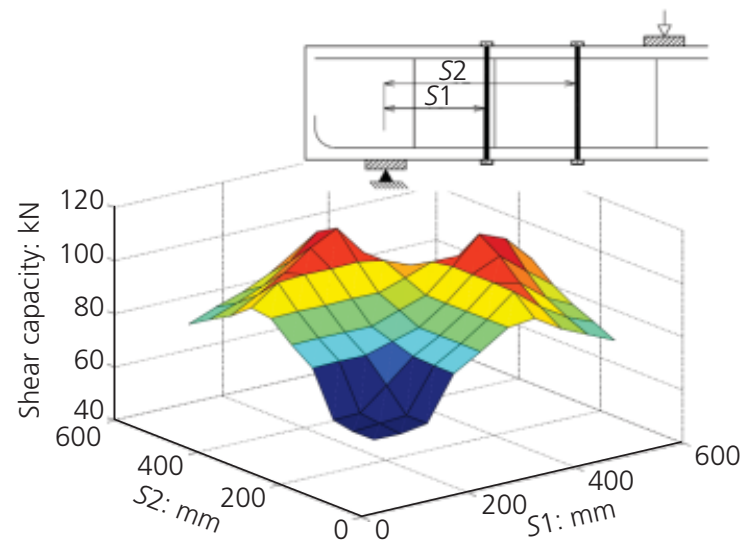

(a)

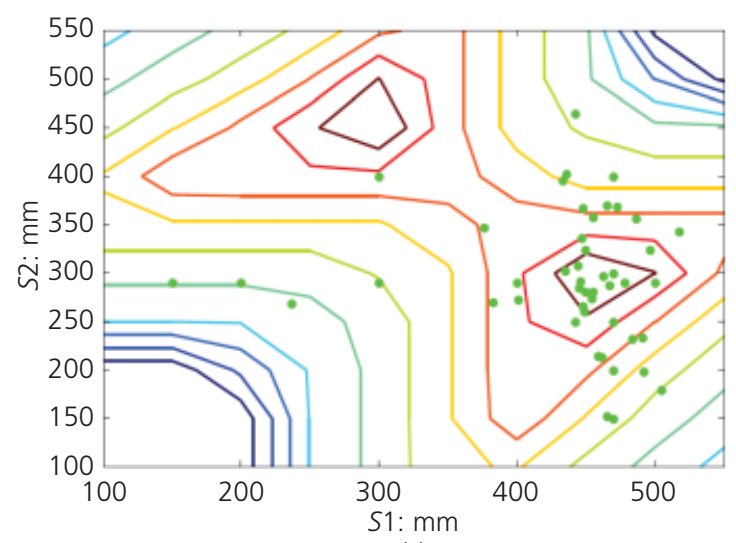

(c)

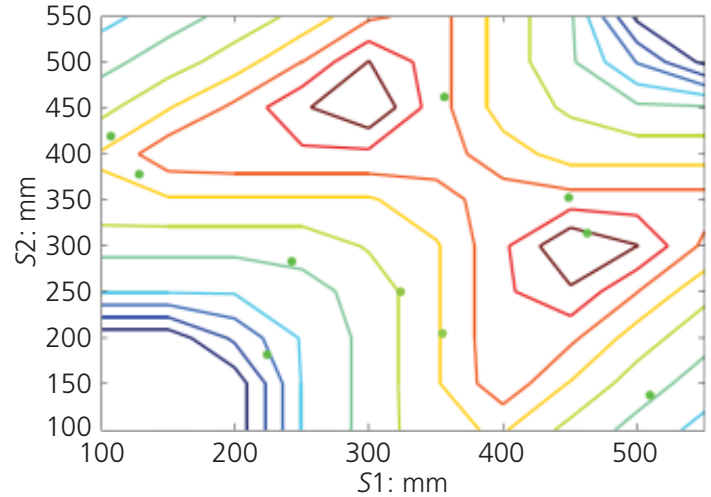

(b)

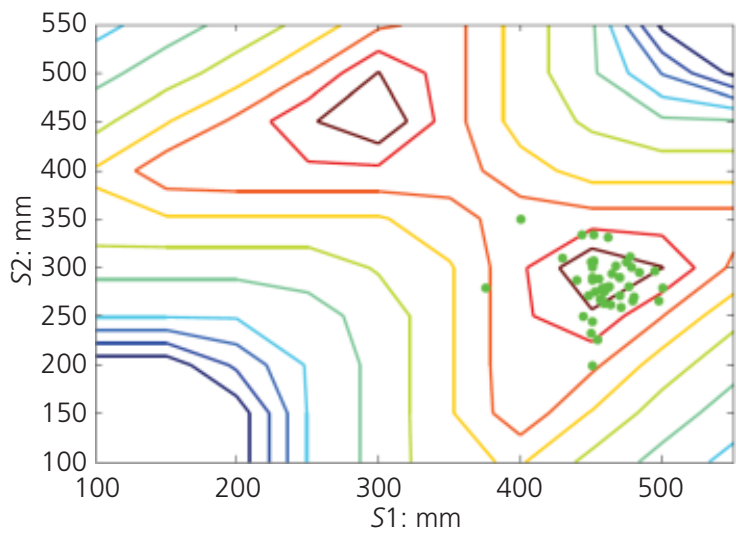

(d)

Figure 8. Optimum carbon fibre reinforced polymer strap location search in the modified compression field theory design space:

(a) design space; (b) initial random solutions for the genetic algorithm (GA) and particle swarm optimisation (PSO); (c) GA solutions over 16-20 generations; (d) PSO solutions over 16-20 generations

\section{Discussion and further parametric studies}

Trade-offs associated with the cost of the CFRP material, the strap installation, the strap prestressing and labour were investigated. Using the beam parameters described previously, the number of straps $n_{\mathrm{S}}$ (two or three), the number of layers per strap $n_{\mathrm{L}}$ (five, 10,15 or 20$)$ and the level of initial prestress $n_{\mathrm{P}}(5 \%$, $25 \%$ or $50 \%$ ) were varied. The internal reinforcement was fixed throughout. For the three-strap case, $S 1, S 2$ and $S 3$ denote the distance to each strap from the beam support. The maximum shear strength is highlighted in Tables 2 and 3 where $a$ and $V_{\text {fle }}$ denote the shear span length and shear force associated with the flexural capacity, respectively.

The ultimate shear strength predictions of the MCFT and SFT methods differ. For example, the MCFT results (Table 2) reveal that the full flexural strength can be achieved with either two tenlayer CFRP straps or three five-layer CFRP straps, with a 50\% initial prestress level at their optimum locations. While these are also good combinations according to the SFT (Table 3), the predicted SFT shear strengths are lower than the flexural capacity. Note that, as previously mentioned, Yapa (2011) argued that SFT slightly underpredicts the shear capacity of CFRP retrofitted beams. For both theories, the similar capacities of the two tenlayer and the three five-layer strap results suggest that with 50\% prestress the CFRP material usage could be optimised by using less stiff straps at closer spacings. If only a nominal prestress is possible $\left(n_{\mathrm{P}}=5 \%\right)$, the MCFT results suggest that the flexural strength can instead be achieved by using either two 20-layer or three 15-layer CFRP straps at their optimum locations. The SFT predictions suggest that of these two options, the three-strap combination would be preferable.

Regardless of the number of straps, CFRP tape layers or initial prestress level, the optimum CFRP strap locations from the two approaches are fairly similar for a given number of straps. For the two-strap case, the average optimum locations are $0.41 a$ and $0.66 a$ compared with $0.40 a$ and $0.60 a$ for the MCFT and SFT, respectively. For the three-strap case, the average optimum locations are $0.37 a, 0.54 a$ and $0.71 a$ compared with $0.38 a, 0.51 a$ and $0.63 a$ for the MCFT and SFT, respectively. The standard deviation for all the strap locations is less than $2 \%$. The optimum strap locations differ from what would be expected if the 


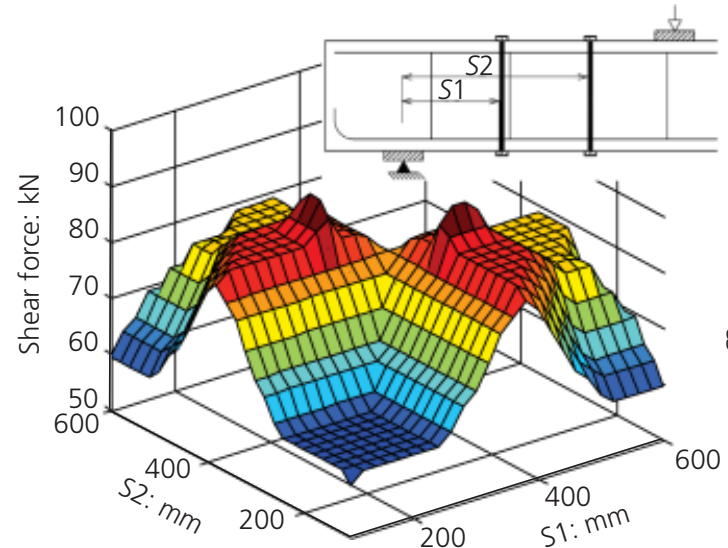

(a)

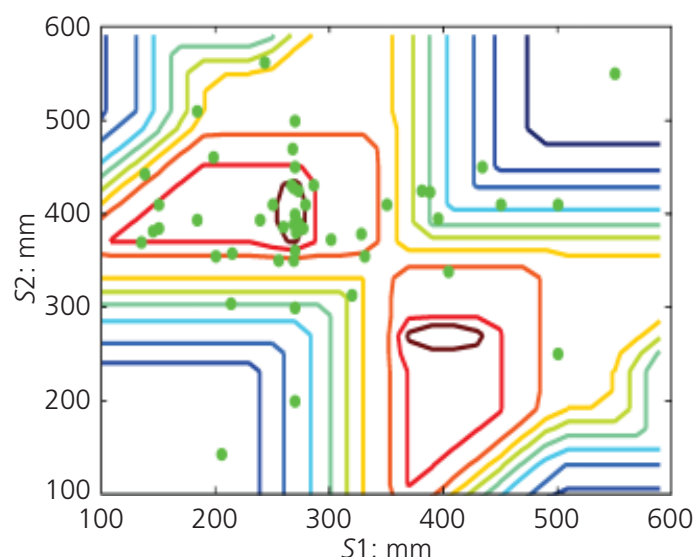

(c)

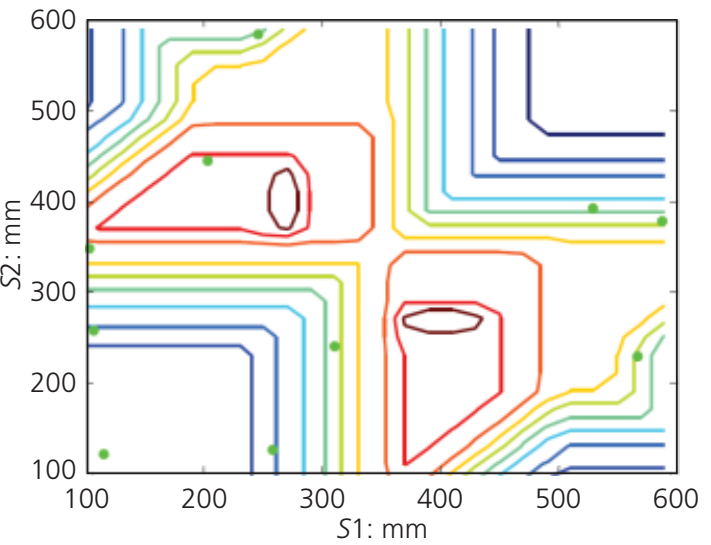

(b)

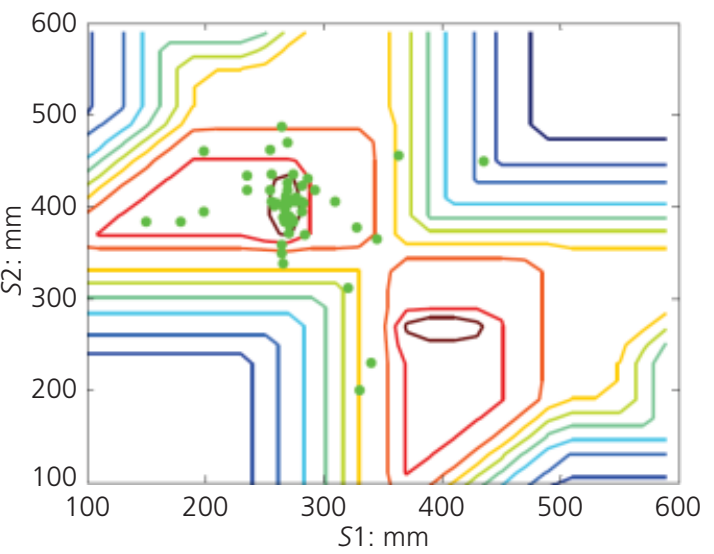

(d)

Figure 9. Optimum carbon fibre reinforced polymer strap location search for the shear friction theory design space: (a) design space; (b) initial random solutions for the genetic algorithm (GA) and particle swarm optimisation (PSO); (c) GA solutions over 16-20 generations; (d) PSO solutions over 16-20 generations

locations were evenly spaced $(0.33 a, 0.67 a$ for a two-strap case and $0 \cdot 25 a, 0 \cdot 50 a, 0 \cdot 75 a$ for a three-strap case) and this deviation is more significant in the three-strap case. The optimum spacing between the straps is smaller than the spacing between a strap and either the support or load point. The MCFT optimum strap locations are also not symmetric around the mid-length of the shear span because the MCFT predicted shear strength reduces with increasing bending moment (Yapa, 2011). Unlike in the MCFT results, all the SFT optimum strap locations are fairly symmetric around the mid-length of the beam but, as implemented, the SFT formulation does not consider the influence of the bending moment on the shear strength. So it is important to note that the optimisation reflects the underlying evaluation method.

As the prestress was varied as a percentage of the strap capacity, when the number of CFRP strap layers increases, both the initial preforce and the force generated in the strap due to cracking increase. The MCFT results in Table 2 demonstrate that when the total CFRP strap force increases due either to an increase in the number of layers or prestress, the optimum locations move outwards and the spacing between the straps increases. The vertical stress in the regions bounded by straps is influenced by the strap force, whereas the vertical stress in the regions adjacent to the beam support and load point reflect both the strap force and total shear force (Yapa and Lees, 2014). Therefore, with increasing strap force, the balance between the shear strength of the regions alters and the shear strength capacities of the strap regions become greater than those of the other regions. To rebalance the shear strengths between the regions, the optimum locations of the CFRP straps have to move outwards. When the strap force increases (due to increase in the strap stiffness or initial prestress level), the SFT also predicts an increase in the spacing between the CFRP straps. According to the SFT, at the optimum CFRP strap locations, the shear strength of the potential shear cracks associated with the strap locations becomes similar. As the force in the straps increases, the shear strength of the crack planes that intersect the straps becomes greater than the shear strength of the crack planes that do not intersect the straps. 


\begin{tabular}{|c|c|c|c|c|c|c|c|}
\hline \multicolumn{3}{|c|}{ Strap design } & \multicolumn{3}{|c|}{ Optimum strap locations } & \multirow[t]{2}{*}{$V: k N$} & \multirow[t]{2}{*}{$\frac{V}{V_{\text {fle }}}$} \\
\hline$n_{S}$ & $n_{\mathrm{L}}$ & $n_{p}$ & S1/a & $S 2 / a$ & S3/a & & \\
\hline 2 & 5 & 25 & 0.45 & 0.64 & - & $98 \cdot 7$ & 0.86 \\
\hline 2 & 5 & 50 & 0.42 & 0.65 & - & $105 \cdot 4$ & 0.91 \\
\hline 2 & 10 & 25 & 0.42 & 0.67 & - & $111 \cdot 2$ & 0.96 \\
\hline 2 & 10 & 50 & 0.39 & 0.68 & - & $114 \cdot 0$ & 1.00 \\
\hline 2 & 15 & 5 & 0.41 & 0.65 & - & $108 \cdot 5$ & 0.94 \\
\hline 2 & 20 & 5 & 0.39 & 0.67 & - & $114 \cdot 0$ & 1.00 \\
\hline Mean & & & 0.41 & 0.66 & - & - & - \\
\hline SD & & & 0.02 & 0.02 & - & - & - \\
\hline 3 & 5 & 25 & 0.39 & 0.54 & 0.69 & $106 \cdot 3$ & 0.92 \\
\hline 3 & 5 & 50 & 0.36 & 0.54 & 0.72 & 114.0 & 1.00 \\
\hline 3 & 10 & 5 & 0.36 & 0.53 & 0.69 & $109 \cdot 0$ & 0.95 \\
\hline 3 & 10 & 25 & 0.36 & 0.53 & 0.72 & 114.0 & 1.00 \\
\hline 3 & 15 & 5 & 0.36 & 0.54 & 0.72 & 114.0 & 1.00 \\
\hline Mean & & & 0.37 & 0.54 & 0.71 & - & - \\
\hline SD & & & 0.01 & 0.01 & 0.02 & - & - \\
\hline
\end{tabular}

Table 2. Optimum carbon fibre reinforced polymer strap locations predicted by the modified compression field theory (based on ultimate shear strength predictions)

\begin{tabular}{|c|c|c|c|c|c|c|c|}
\hline \multicolumn{3}{|c|}{ Strap design } & \multicolumn{3}{|c|}{ Optimum strap locations } & \multirow[t]{2}{*}{$V: \mathrm{kN}$} & \multirow[t]{2}{*}{$\frac{V}{V_{\mathrm{fle}}}$} \\
\hline$n_{S}$ & $n_{\llcorner}$ & $n_{\mathrm{P}}$ & S1/a & $S 2 / a$ & S3/a & & \\
\hline 2 & 5 & 25 & 0.42 & 0.58 & - & $83 \cdot 3$ & 0.73 \\
\hline 2 & 5 & 50 & 0.40 & 0.60 & - & $92 \cdot 8$ & 0.81 \\
\hline 2 & 10 & 25 & 0.39 & 0.61 & - & $96 \cdot 0$ & 0.84 \\
\hline 2 & 10 & 50 & 0.38 & 0.61 & - & $107 \cdot 1$ & 0.94 \\
\hline 2 & 15 & 5 & 0.42 & 0.58 & - & $91 \cdot 6$ & 0.80 \\
\hline 2 & 20 & 5 & 0.39 & 0.60 & - & 94.7 & 0.83 \\
\hline Mean & & & 0.40 & 0.60 & - & - & - \\
\hline SD & & & 0.02 & 0.01 & - & - & - \\
\hline 3 & 5 & 25 & 0.39 & 0.51 & 0.61 & $93 \cdot 7$ & 0.82 \\
\hline 3 & 5 & 50 & 0.36 & 0.51 & 0.64 & $105 \cdot 7$ & 0.93 \\
\hline 3 & 10 & 5 & 0.39 & 0.51 & 0.61 & $91 \cdot 1$ & 0.80 \\
\hline 3 & 10 & 25 & 0.36 & 0.51 & 0.65 & $109 \cdot 1$ & 0.96 \\
\hline 3 & 15 & 5 & 0.38 & 0.51 & 0.62 & $102 \cdot 3$ & 0.90 \\
\hline Mean & & & 0.38 & 0.51 & 0.63 & - & - \\
\hline SD & & & 0.01 & 0.00 & 0.02 & - & - \\
\hline
\end{tabular}

Table 3. Optimum carbon fibre reinforced polymer strap locations predicted by the shear friction theory

To rebalance the shear strength associated with these cracks, the optimum strap locations change. Hence for both the MCFT and SFT results the optimum strap locations are influenced by the force in the CFRP straps.

\section{Conclusions}

The use of stochastic optimisation methods for the evaluation and optimisation of RC beams retrofitted with prestressed CFRP straps was investigated. Two stochastic optimisation algorithms, 
namely the PSO and GA, were used in conjunction with two shear strength evaluation methods, the MCFT and SFT. It was found that the stochastic optimisation methods could be used to reduce the computational cost associated with the evaluation of the shear strength capacity and the search for the optimum CFRP strap layouts. The preferred algorithm, in terms of speed of convergence and the proximity of the converged solution to the optimum, depended on the topology of the design space. Whereas the PSO performed better with the MCFT evaluations, the GA was superior in conjunction with the SFT evaluations. Irrespective of the evaluation method, when searching the strengthened design space the PSO converged more quickly than the GA on the strengthening layouts associated with the highest shear strength capacity. The 'optimum' CFRP strap layouts necessarily reflect the underlying shear theory. So the small differences between the most efficient MCFT and SFT strengthened layouts were due to the different assumptions and theoretical basis for the two evaluation models.

\section{Acknowledgements}

The first author is grateful for the financial support provided by the Cambridge Commonwealth Trust, the Overseas Research Studentship and Churchill College. The authors are also appreciative of the technical support and assistance provided by EMPA, Dr X.S. Yang, Dr G.T. Parks, Dr C.T. Morley, Mr M.R. Touhey and Mr S.J. Holder.

\section{REFERENCES}

Bentz EC and Collins MP (2006) Development of the 2004 Canadian Standards Association (CSA) A23. 3 shear provisions for reinforced concrete. Canadian Journal of Civil Engineering 33(5): 521-534.

Collins MP and Mitchell D (1987) Prestressed Concrete Basics. Canadian Prestressed Concrete Institute, Ontario, Canada.

De Lorenzis L and Nanni A (2001) Shear strengthening of reinforced concrete beams with near-surface mounted fiberreinforced polymer rods. ACI Structural Journal 98(1): 60-68.

Dirar S, Lees JM and Morley CT (2013) Precracked reinforced concrete T-beams repaired in shear with prestressed carbon fiber-reinforced polymer straps. ACI Structural Journal 110(5): $855-866$.

Goldberg DE (1989) Genetic Algorithms in Search, Optimization and Machine Learning. Addison-Wesley, Reading, MA, USA.

Govindaraj V and Ramasami JV (2007) Optimum detailed design of reinforced concrete frames using genetic algorithms. Engineering Optimisation 39(4): 471-494.

Hoult NA and Lees JM (2009a) Efficient CFRP strap configurations for the shear strengthening of reinforced concrete T-beams. ASCE Journal of Composites for Construction 13(1): 45-52.

Hoult NA and Lees JM (2009b) Modelling of an un-bonded CFRP strap shear retrofitting system for reinforced concrete beams. ASCE Journal of Composites for Construction 13(4): 292301 .
Hu X (2006) Particle Swarm Optimization. See http:// www.swarmintelligence.org/index.php (accessed 06/03/2014).

Keane AJ (1995) Genetic algorithm optimisation of multi-peak problems: studies in convergence and robustness. Artificial Intelligence in Engineering 9(2): 75-83.

Kesse G and Lees JM (2007a) Experimental behaviour of reinforced concrete beams strengthened with prestressed CFRP shear straps. ASCE Journal of Composites for Construction 11(4): 375-383.

Kesse G and Lees JM (2007b) Nonlinear FE analysis of cracks in tension and shear. Magazine of Concrete Research 59(4): 233-244.

Lees JM and Winistörfer AU (2011) Non-laminated FRP strap elements for reinforced concrete, timber and masonry applications. ASCE Journal of Composites for Construction 15(2): 146-155.

Lees JM, Winistörfer AU and Meier U (2002) External prestressed carbon fiber reinforced polymer straps for shear enhancement of concrete. ASCE Journal of Composites for Construction 6(4): $249-256$.

Liu Y, Qin Z, Shi Z and Lu J (2007) Centre particle swarm optimisation. Neurocomputing 70(4): 672-679.

Loov RE (1998) Review of A23. 3-94 simplified method of shear design and comparison with results using shear friction. Canadian Journal of Civil Engineering 25(3): 437-450.

Matous K, Leps M, Zeman J and Sejnoha M (2000) Applying genetic algorithms to selected topics commonly encountered in engineering practice. Computer Methods in Applied Mechanics and Engineering 190(13-14): 1629-1650.

Perera R, Vique J, Arteaga A and De Diego A (2009) Shear capacity of reinforced concrete members strengthened in shear with FRP by using strut and tie models and genetic algorithms. Composites Part B: Engineering 40(8): 714-726.

Rafiq MY and Southcombe C (1998) Genetic algorithms in optimal design and detailing of reinforced concrete biaxial columns supported by a declarative approach for capacity checking. Computers \& Structures 69(4): 443-457.

Sahab MG, Ashour AF and Toropov VV (2005) Cost optimisation of reinforced concrete flat slab buildings. Engineering Structures 27(3): 313-322.

Shi Y and Eberhart RC (1998) A modified particle swarm optimizer. Proceedings of the IEEE Congress on Evolutionary Computation (CEC 1998), Piscataway, NJ, USA, pp. 69-73.

Teng JG, Lam L and Chen JF (2004) Shear strengthening of RC beams with FRP composites. Progress in Structural Engineering and Materials 6(3): 173-184.

Vecchio FJ and Collins MP (1986) The modified compression field theory for reinforced concrete elements subjected to shear. ACI Structural Journal 83(2): 219-231.

Winistörfer AU (1999) Development of Non-laminated Advanced Composite Straps for Civil Engineering Applications. $\mathrm{PhD}$ thesis, Department of Engineering, University of Warwick, Warwick, UK. 
Wolpert DH and Macready WG (1997) No free lunch theorems for optimization. IEEE Transactions on Evolutionary Computation 1(1): 67-82.

Yang XS, Lees JM and Morley CT (2006) Application of virtual ant algorithms in the optimization of CFRP shear strengthened precracked structures. Proceedings of the 6th International Conference on Computational Science (ICCS
2006), Springer, Berlin, Germany, pp. 834-837.

Yapa HD (2011) Optimum Shear Strengthening of Reinforced Concrete Beams. PhD Thesis, Department of Engineering, University of Cambridge, Cambridge, UK.

Yapa HD and Lees JM (2014) Rectangular reinforced concrete beams strengthened with CFRP straps. ASCE Journal of Composites for Construction 18(1): 04013032.

\section{WHAT DO YOU THINK?}

To discuss this paper, please email up to 500 words to the editor at journals@ice.org.uk. Your contribution will be forwarded to the author(s) for a reply and, if considered appropriate by the editorial panel, will be published as a discussion in a future issue of the journal.

Proceedings journals rely entirely on contributions sent in by civil engineering professionals, academics and students. Papers should be 2000-5000 words long (briefing papers should be 1000-2000 words long), with adequate illustrations and references. You can submit your paper online via www.icevirtuallibrary.com/content/journals, where you will also find detailed author guidelines. 